\title{
Conduction Mechanism in Polyaniline -Polyacrylic Acid Blend
}

\author{
Wael. A. S. Abdul Ghafor \\ Hameed A.hamdi \\ Nadhim A.Abdullah \\ Hesham A.Saleh \\ Materials Science Department / Polymer Research Center, \\ Basra University
}

Received

15 / 02 / 2007
Accepted

07 / 05 / 2008

الخلاصة

في هذا البحث نم دراسة التوصيل الكهربائي و اليات التوصيل وطاقات التشيط لأغشية رقيقة

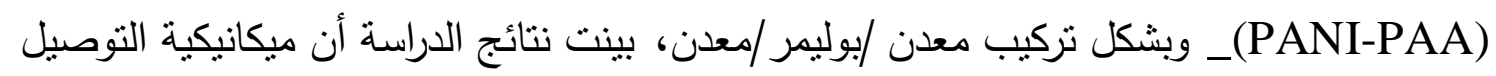

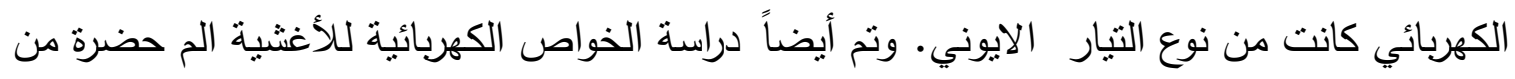

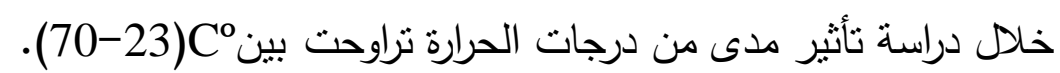

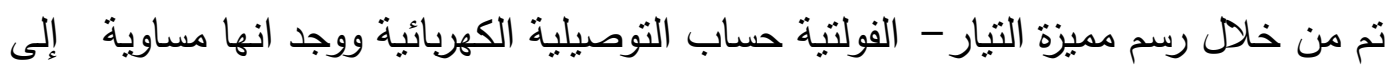

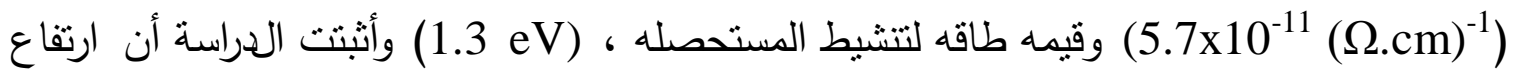

درجة الحرارة يؤدي الى زيادة في مقدار التوصيلية الكهربائية للأغثية المحضرة ضدن مدى درهية الحرارة أعلاه.

\section{Abstract:}

The electrical properties of polyaniline-polyacrilic acid blend are reported using Al/Polymer/Al structured. The D.C. conductivity is measured in the temperature range $(23-70) \mathrm{C}^{\circ}$ via two probe method. The current was measured at steady state conditions. The domains conduction mechanism was identified as Ionic conduction. The D.C conductivity and the activation energy were estimated to be $5.7 \times 10^{-11}(\Omega . \mathrm{cm})^{-1}$ while activation energy is $(1.3 \mathrm{eV})$, and dark DC bulk conductivity of blend was observed to increase orders of magnitude in the investigated temperature range. 


\section{1- Introduction:}

Conjugated polymers are intrinsically semiconducting materials. They lack intrinsic mobile charge, but are able to transport charge generated by light, injected by electrodes, or provided by chemical dopants ${ }^{(1-2)}$. A large number of conjugated polymers that exhibit high conductivity after doping have been synthesized and studied ${ }^{(1-4)}$. however, difficulties encountered in processing these materials in the form of solution or melts have hindered. their development in many applications of all the difficult modification techniques available, one of the most medley studied and applied is the formation of blends of different origins, conducting polymers blends are in facts some suitable compositions of a conducting polymer with one or more insulating polymers, so that their desirable properties are combined successfully ${ }^{(5-9)}$.

Such blends of polymers with conducting polymers are promising materials in the electronic area. One of the most important application for these blends is their use in the domain of antistatic materials and for electromagnetic shielding (EMI) ${ }^{(9-11)}$.

PANI, is one of the conducting polymers that has attracted considerable one of the best conduits for the preparation of polymer-based conducting polymer composites ${ }^{(5,12-13)}$, because of that PANI high stability toward air and moisture, high electrical conductivity ${ }^{(1,14)}$ and unique red ox properties $^{(1-2,15)}$, recently, significant progress of PANI have been achieved in the preparation of processable form ${ }^{(14-18)}$.

Among insulating matrix polymer, polyacrylic acid and it is derivatives as polyacrolites, substituted polyacrylate and their inter pentene rating polymers network IPN ${ }^{(19-20)}$ are one of the fast growing classes of polymeric materials for their wide range application in dental industries ${ }^{(21)}$, synthetic films manufacturing ${ }^{(22)}$, hydro gel application ${ }^{(23)}$, ceramic binder $^{(24)}$, polyacrolyte application ${ }^{(25)}$, ion exchange resin ${ }^{(26)} \ldots .$. ets.

Recently several conductive blends of proton Ted PANI with insulating polymers have been reported ${ }^{(5-6,9,27)}$. This technique allows to obtain conducting films characterized by low percolation threshold $(<1 \%)$ with mechanical properties better than those of pure PANI films ${ }^{(9-10,28)}$.

In this study, pure PANI- Polyacrylic Acid was synthesis using condensation polymerization and parameters corresponding to the homogenous film were identifies. Electrical conduction mechanism for the blend was analyzed. 


\section{2- Experimental:}

PANI-PAA blend was synthesized by condensation copolymerization of polyacrylic acid $\left(\mathrm{m}_{\mathrm{w}}=600\right)$ with aniline monomer were three necks reaction vessel of $520 \mathrm{ml}$ volume changed with (0.1) mole aniline monomer and(0.1) mole PAA and (100)ml DMSO as a solvent in the presence $\mathrm{H}_{3} \mathrm{Po}_{4}$ as external acid catalyst. The reaction vessel provided by condenser mechanical stirrer and thermometer. The mixture was heated gradually (40110.) \mathrm{C}$ by oil bath under reflex conditions for (10) hours.

The product was evaporated from the excess DMSO after cooled to room temperature. Blend as thin film has been deposited on aluminum substrate, were these substrates cleaned by pure acetone and washed with distilled water and dried after that use that as a lower-electrode at normal aquarium condition using cast method Then dried at room temperature for $24 \mathrm{hrs}$, then heated gradually up to $(50) \mathrm{C}$ by a rate $10 \mathrm{C} / 30 \mathrm{~min}$. Then the coasted films were kept at this temperature for $16 \mathrm{hrs}$ to complete curing.

Aluminum metal (99.99\%) was carried out using evaporation system model (Varian 3117) under vacuum pressure better than $\left(10^{-6}\right.$ torr) as upper electrode, through a circular mask $0.03 \mathrm{~cm}^{2}$ to obtain sandwich configuration. All (current-voltage) measurement was carried in dark and electrical shield.

\section{3- Results and Discussion:}

The experimental circuit for measuring D.C conductivity is illustrated in fig.(1). Electrical conductivity of the blend was measured at different temperature combined with steady state conditions. The I-T relation in fig (2) may explain as fellows :the current flowing in the sample; expressed by the relation $\left\{\mathrm{J}=\mathrm{n} \mathrm{q} \mu \mathrm{E}^{*}\right\}$ where: $\mathrm{J}, \mathrm{q}, \mathrm{n}, \mu$, and $\mathrm{E}^{*}$ are the current density, carrier charge, carrier density, carrier mobility and the effective field strength in the bulk of the polymer respectively. One of the mechanism to explain the drop of the current carriers (n) with in the sample is due to their arrival at the electrode (clean - up - effect $)^{(29)}$. The second mechanism is the effective drop of the electric field $\left(\mathrm{E}^{*}\right)$ in the bulk of the sample placed between the two electrodes due to the space charge effect of the carrier of the carrier drifting to the electrode. Since the current in the equation above; directly related to $\mathrm{n}$ and $\mathrm{E}^{*}$, therefore, the current decrease with time because the carrier density and the effective electric field decrease with the time, which in turn decrease the current after the application of voltage ${ }^{(30)}$.

The relation between current and voltage at different temperature is shown in fig.(3), this relation is plotted on a log-log scale as shown in fig.(4). 
From fig.(3) \& fig.(4) we can see a behavior of two regions. First region in which a linear relationship between current and voltage at lower applied voltage 50 volts Ohm's law is applied and current density is directly proportional to the applied field which influence only carrier velocity and ensure that thermally generated charge carriers are affected by current limits.

As the applied field increases, there will be an increase probability of injection of excess charge in the film from electrodes and hence a departure from Ohm's law is observed (See fig. (3)). Ionic conduction can be suggested here to explain the behavior of current were Baker and Thomas conclude that this conduction was important at very high field ${ }^{(31)}$. We also can conclude that the existence of free ions (cation and anion pairs) which is unbounded with big molecules are the causes of such conductivity were the ionic conductivity process involves a cooperative interaction between the mobile ions and polymer matrix.

Activation energy was estimated from the slope of the line obtained from plotting electrical conductivity versus the reciprocal of temperature (1/T), fig.(5). The result of activation energy obtained was (1.3) eV which is large amount and means that more energy is required to release electron from deep and shallow traps, another result was observed from fig.(5) that conductivity increasing with increasing of temperature in the range (23$80)^{\circ} \mathrm{C}$, this is due to the release of extra charge carrier with increasing temperature Fig. (6) shows also the relation between $(\log \sigma)$ and the reciprocal of temperature $(1 / \mathrm{T})$, were a linear relationship was obtained were at high temperature thermal movment of polymer chain segments would be improved, which increased the ionic conductivity, such behavior was also observed in amorphous materials due to the defect ${ }^{(31)}$, while figure (7) shows the relation between $(\log J)$ and E giving another indicate of ionic conduction through low to high field region were the most of migration of ions are localized barrier height were theses barriers comes from the amorphous structure of polymer chains.

\section{4- Conclusion:}

Electrical properties of poly aniline-poly acrylic acid has been studied through measuring (current-voltage) characteristic conduction mechanism in temperature range $(23-80)^{\circ} \mathrm{C}$ have been probed and identified as a space charge limited current-positive charge carriers contributed in conduction mechanism have activation energy (1.3)eV.

The bulk conductivity at room temperature was estimated to be $(5.7 \mathrm{x}$ $\left.10^{-11}\right)(\Omega . \mathrm{cm})^{-1}$, finally it was found that conductivity is increasing with the temperature increase. 


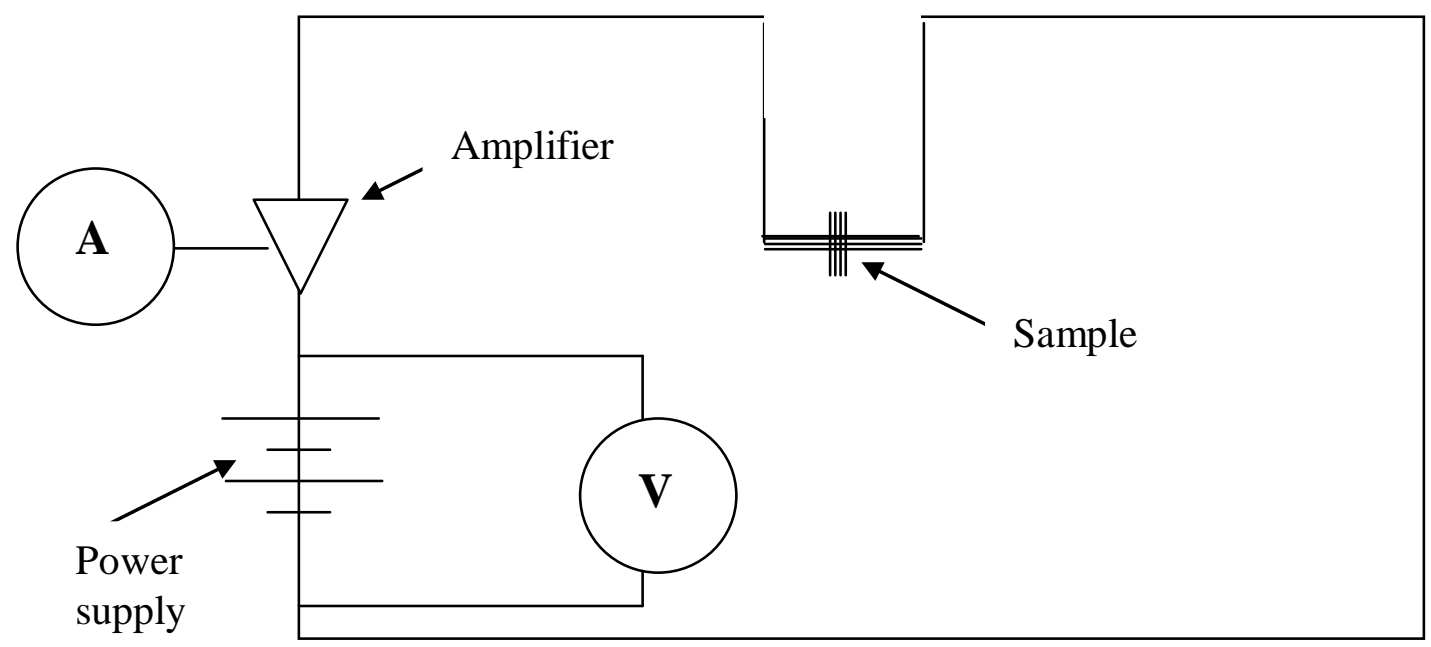

Fig. (1): The measurement circuit of (I-V) characteristic.

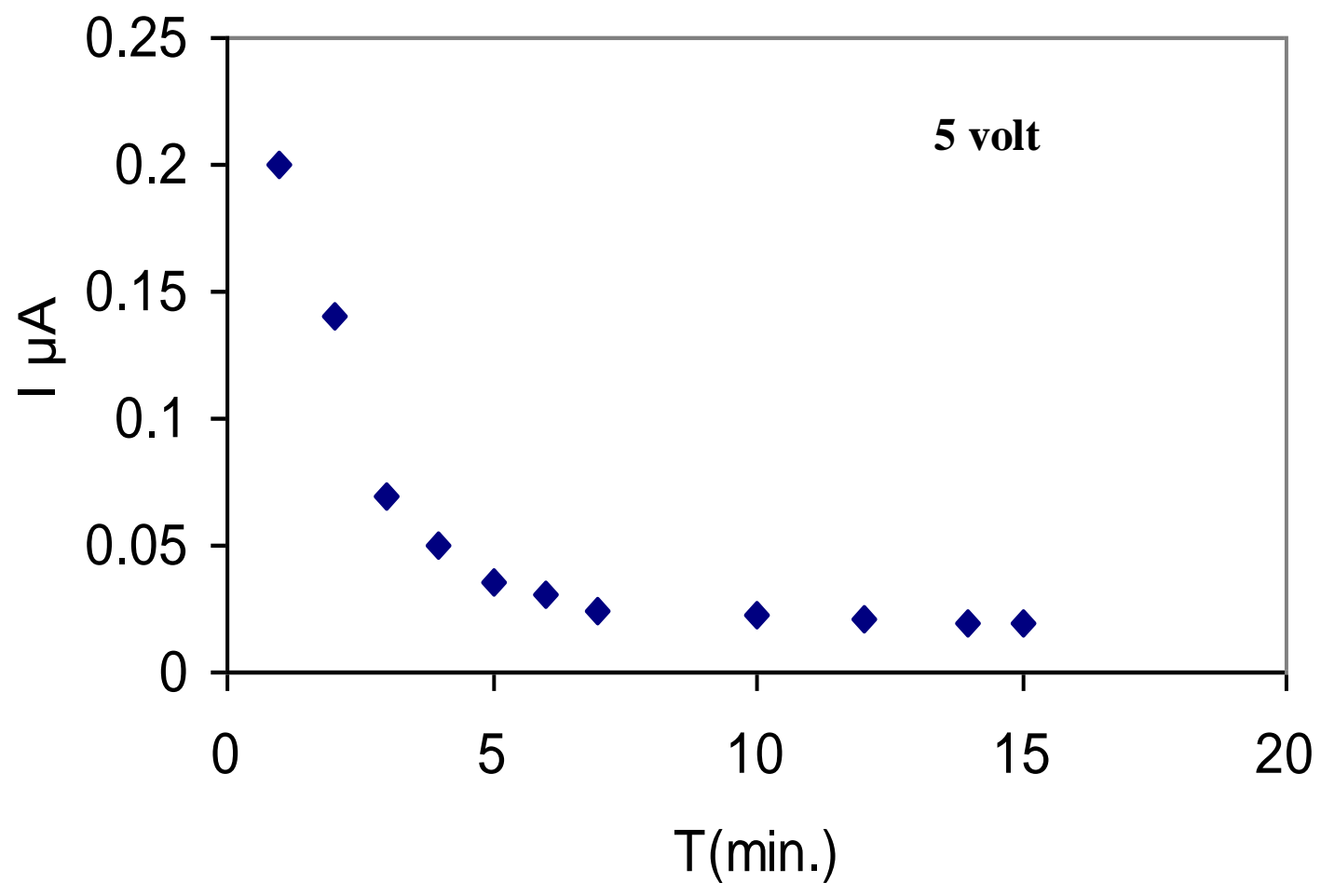

Fig. (2): The relation between current and time. 
Conduction Mechanism in Polyaniline -Polyacrylic Acid Blend.

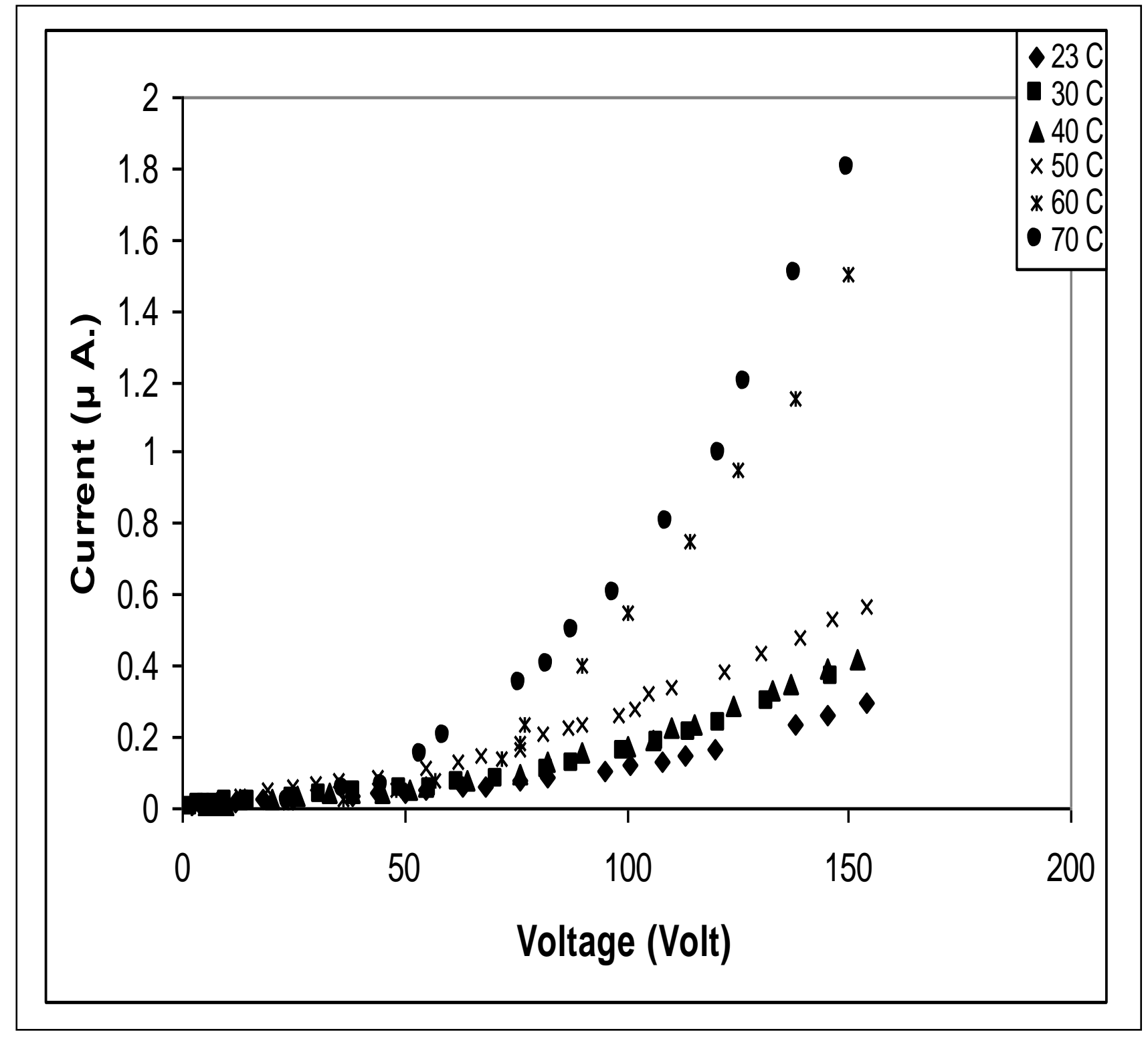

Fig. (3): The (I-V) characteristics at different temperatures. 


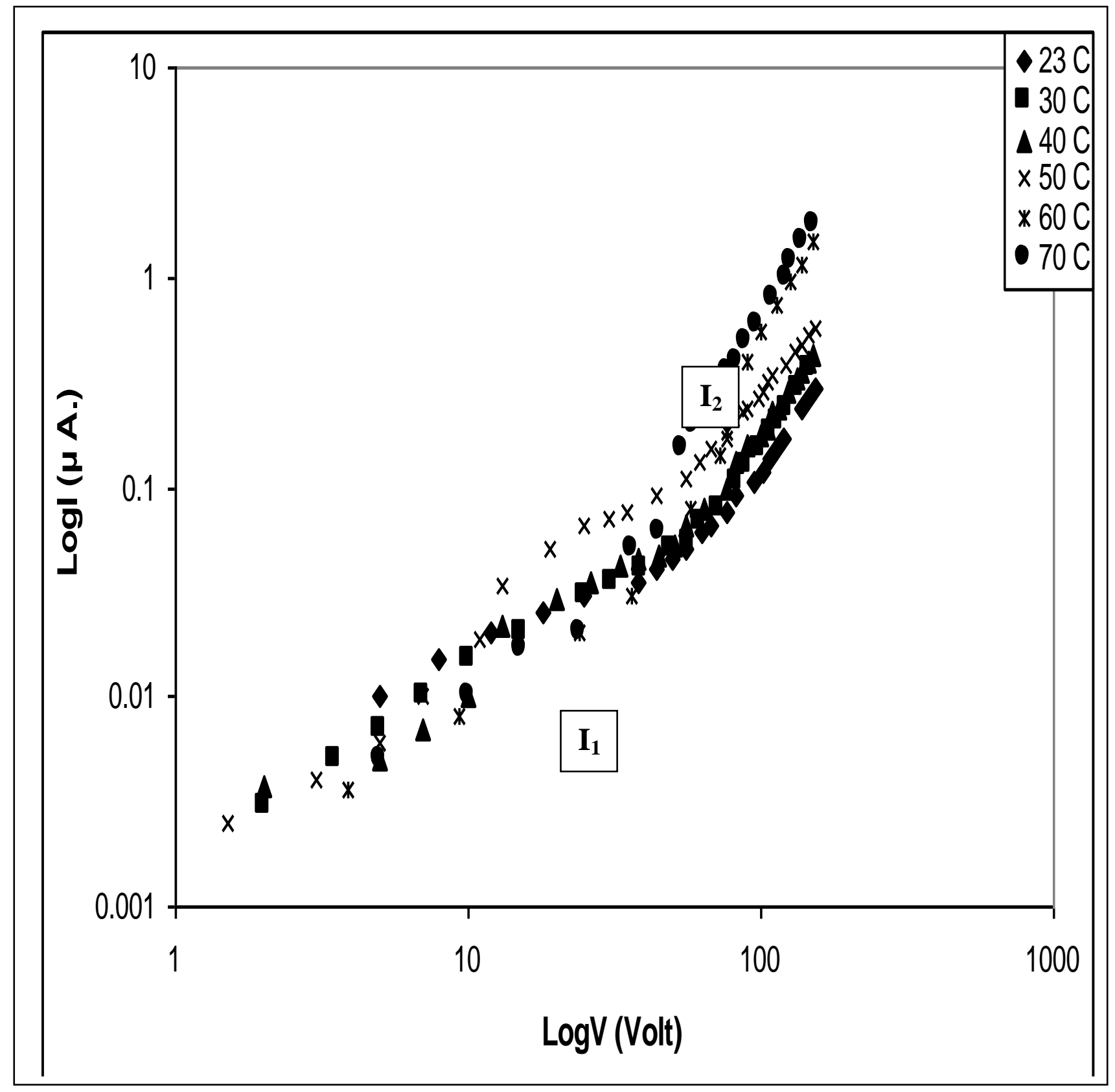

Fig. (4): The (log I-log V) characteristics at different temperatures. 
Conduction Mechanism in Polyaniline -Polyacrylic Acid Blend.

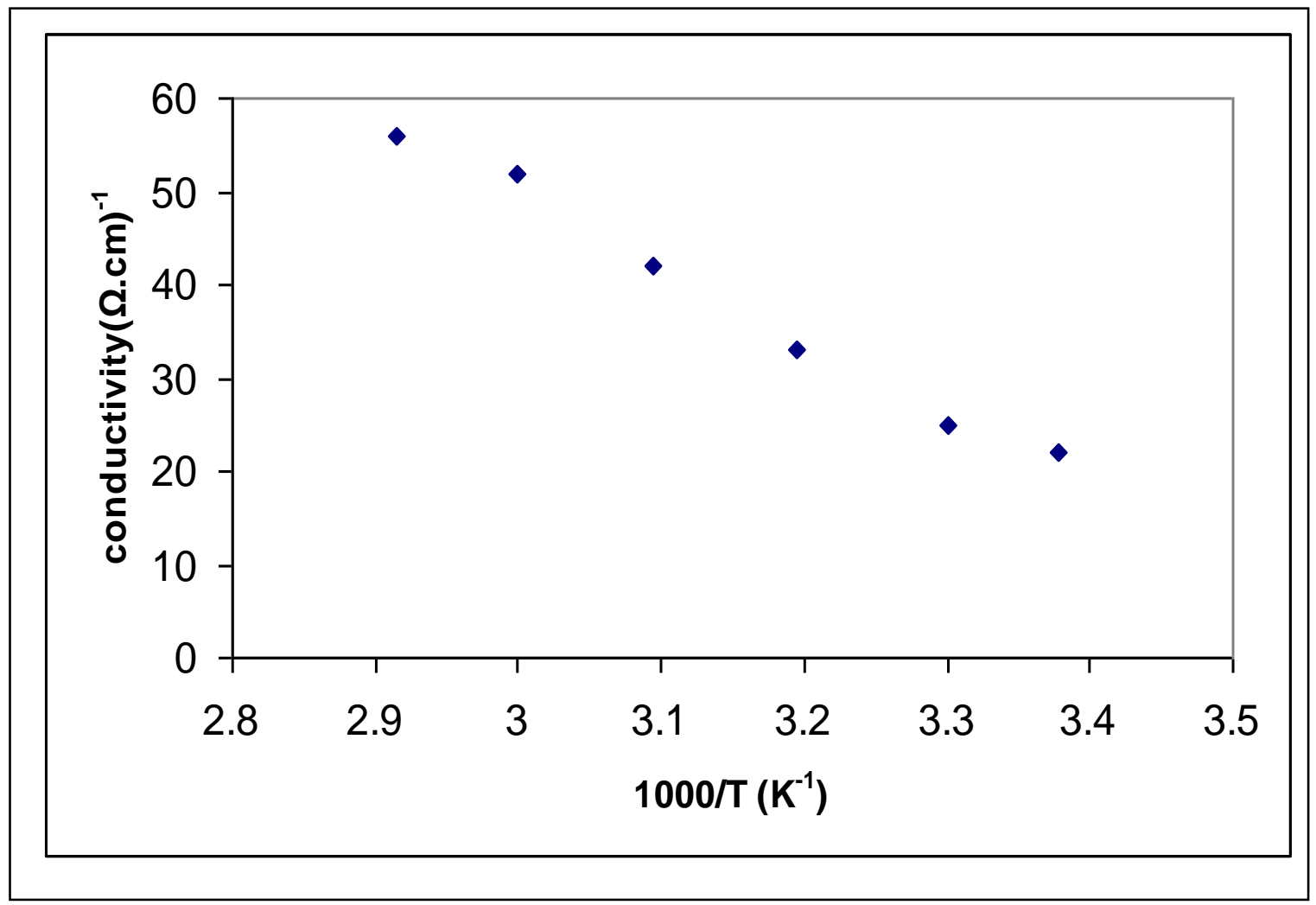

Fig. (5): The relation between conductivity and temperature.

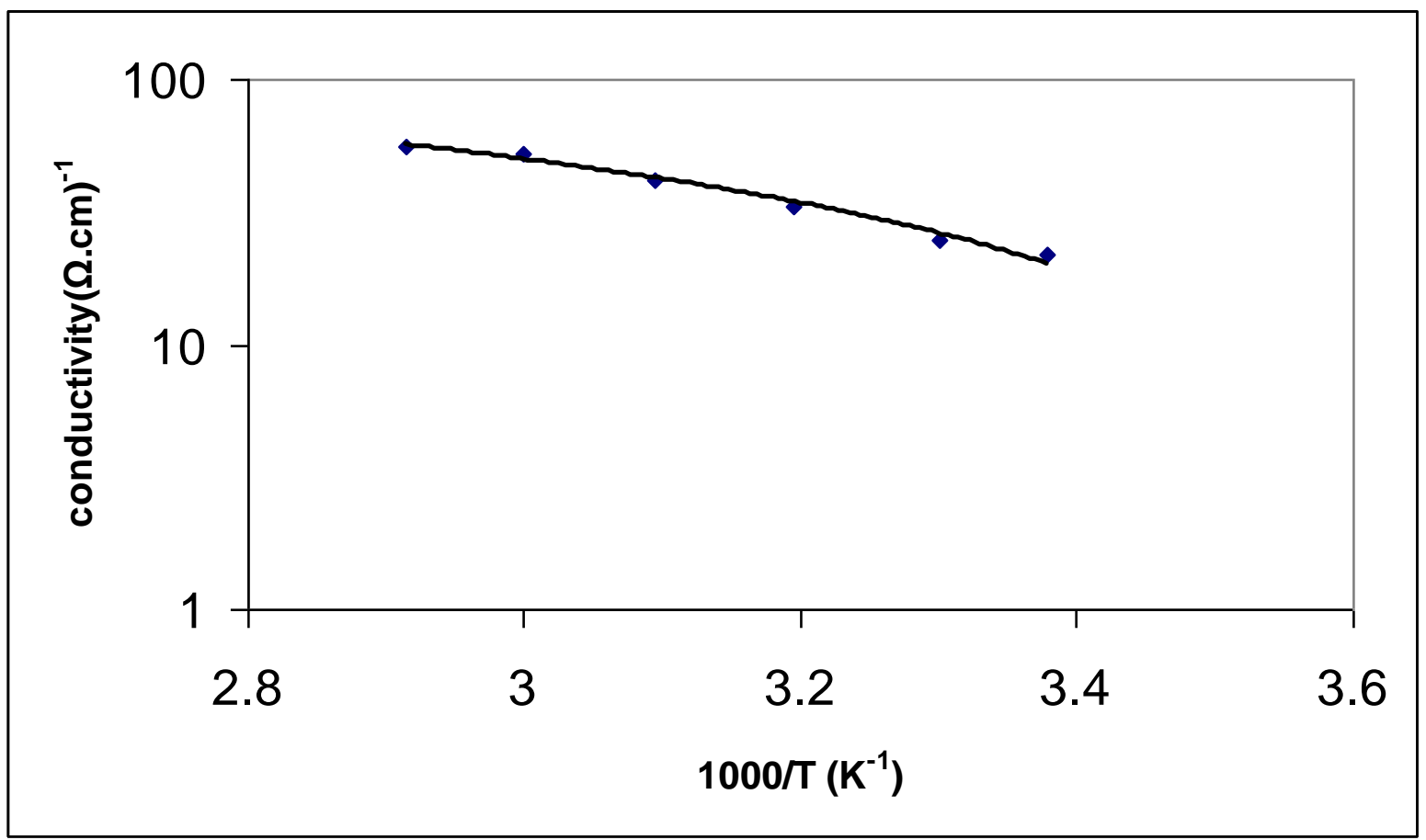

Fig. (6): The relation between $(\log \sigma)$ and temperature. 


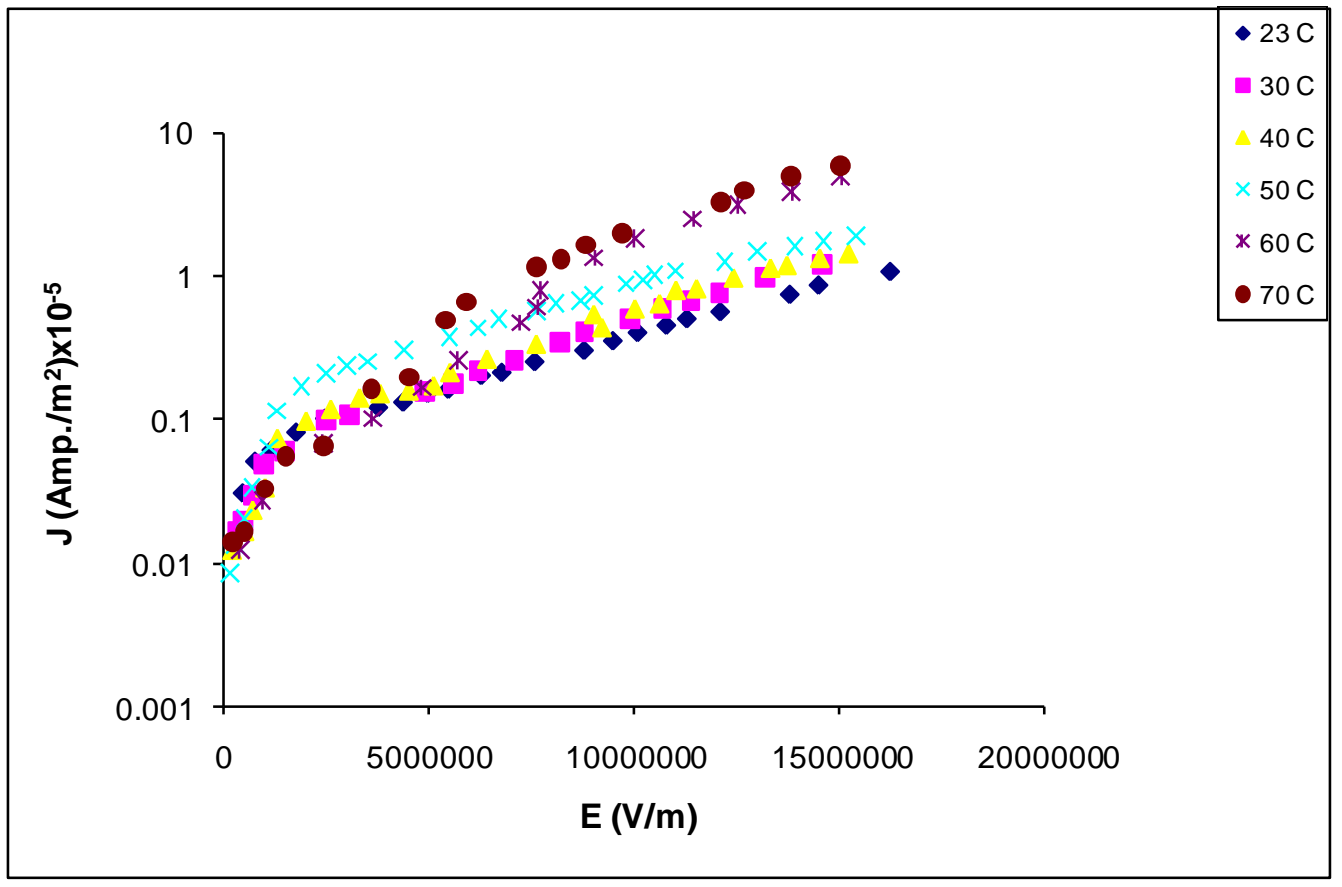

Fig.(7): the relation between $(\log \mathrm{J})$ and effective field strength

\section{$\underline{\text { References }}$}

1) T. A. Shotheim (ed.), "handbook of conductivity polymers", Marcel Dekker, N. Y., (1988).

2) Ullmann's encyclopedia of industrial chemistry, electronic release, Wiky-CVH. Weinheim Germany, 6 th Edition, (2002).

3) Wang Jinwie, M. P. srin iva san, Synthetic metals, 105 (1999) 1-7.

4) H. S. Nalwa (Ed.), "Hand book of organic conductive molecules and polymers", Wiely, England, Vol.3, (1997).

5) Wan-Jin Lee, Yong-Ju Kim and Shin Young Kanng, Synthetic matels 113 (2000) 237-243.

6) O. Niwa, J. chem. Soc. chem commun. (1984) 817.

7) G. Boiteux, A. Ho-Hoang, F. Fache, M. Lemaire, I. Glowaski and J. Ulanki, synthetic metals, 69 (9995) 487-489.

8) Superakas sinha Ray, Materials Research Bulletin, 37 (2002) 813-824.

9) J. Laska, K. Zak and A. Pron, Synthetic metals, 84 (1997) 117-118.

10) V. Jousseaume, M.Mmorsli, A. Bonnet and S. Lefrant, Synthetic metals, 101 (1999) 813-814. 
11) T. Makela, S. Pienimaa, T. Take, S. Jussila and H. Isotalo, Synthetic metals, 85 (1997) 1335.

12) Bidhan C. Roy, Maya Dutta Gupta, Leeua Bohumik,Jayanta K. Ray, Synthetic matels, 130 (2002) 27-33.

13) Wilso A. Gazotti, Jr., Marco-A. Depaoli, synthetic matels, 80 (1996) 163-269.

14) R. L Greene, G. B. Street and L. J. Suter, Phys. Rev. Lett., 34 (1975) 557.

15) Y. Cao, P. Smith, A. J. Heeger, Synthetic matels, 48 (1992) 91.

16) P. Dashora and G. Gupta, polymer vol.37, 2 (1998) 231-239.

17) Y. Cao, P. smith, A. J. Heeger, Synthetic matels 57 (1993) 3514.

18) J. Y. Lee, D. Y. Kim, C. Y. Kim, Synthetic Matels, 74 (1995) 103.

19) A. Shah, R. A. Rytz, H. Xiao, V. E. Gunn and K. C. Frish, J. Coating technology, 62 (1990) 789.

20) I. M. Kamal, G. A. Adam and A. H. ALMawali, Basrah J. of science, 11 (1993) 57.

21) L. Holiday "Ionic Polymer", Applied Science Publishes LID (1975).

22) R. B. Seeymour and H. F. Mark "Application of Polymers", plenum press N. Y. (1988) 903.

23) H. Kawagnchi, M. Kawahara, N. Yaguchi, F. Hoshino and Y. Ohtsuka, Polymer J., 20 (1988) 903.

24) H. S. AL-lami, ust international conference on polymeric materials, Basra, Iraq, (1993) 6-8.

25) R. W. Pysonand, C. Hall, Specialty polymers, N. Y. (1987) 190.

26) A. A. Tossonian, H. H. Hadad and A. T. ALSammarae, Basrah J. of science, part C,12 (1994) 31.

27) F. Hide, B. Schwartz, M. A. Diaz-Garcia and A. J. Heeger, Chem. Phys. Lett., 257 (1996) 424.

28) V. Jousseaume, M. Morsli, A. Bonnet, S. Lefrant, Opt. Mat., 9 (1998) 484.

29) M. S. Al-ajely, Ph.D. thesis, mosul univ., 1993.

30) Migahed and I. A. Elhamid, J. of polymer science, part B, 24, 2631 (1986).

31) R. E. Baker and C. R. Thomas, J. Appl. phys., 34, 87(1964). 